\title{
Teste de micronúcleos em peixes e parâmetros físico-químicos da água da represa Cocais, Minas Gerais
}

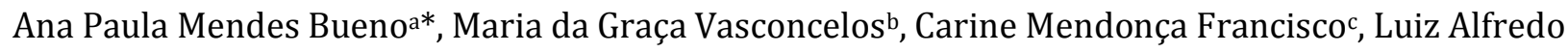 \\ Pavanind \\ a Universidade Federal de Uberlândia, Minas Gerais, Uberlândia 38400-902, Brasil. * anapaulamendesbueno@hotmail.com.br \\ b Instituto de Ciências Agrárias, Universidade Federal de Uberlândia, Minas Gerais, Uberlândia 38400-902, Brasil. \\ c Programa de Pós-Graduação em Genética e Bioquímica, Universidade Federal de Uberlândia, Minas Gerais, Uberlândia 38400-902, Brasil. \\ ${ }^{d}$ Instituto de Química, Universidade Federal de Uberlândia, Minas Gerais, Uberlândia, 38400-902, Brasil..
}

Recebido: 20 julho 2017 / Aceito: 24 setembro 2017 / Publicado online: 27 setembro 2017

\begin{abstract}
Resumo
Os bioindicadores são usados para avaliar mudanças no ambiente aquático. Substâncias químicas incorporadas em ambientes naturais interferem no desenvolvimento desses organismos. A pesquisa teve como objetivo avaliar a qualidade da água da represa Cocais, em Patrocínio, Minas Gerais, utilizando parâmetros físico-químico da água e teste de micronúcleo em peixes. Nesse estudo, foram utilizados peixes da espécie Oreochromis niloticus L. (Tilápia-do-nilo) introduzidos na represa após a sua construção. Material genético de vinte e oito indivíduos foi coletado em dois pontos, P1 na nascente e P2 na represa. A análise citológica foi realizada utilizando-se microscópio óptico, sendo examinados 4000 eritrócitos por peixe. Para a caracterização físico-química das amostras de água foram realizadas duas coletas no período de chuva e de seca, tanto na nascente como na represa. Os parâmetros analisados (turbiez, pH, oxigênio dissolvido - OD, sólidos totais dissolvidos - SDT), nitrato e nitrogênio amoniacal foram inferiores aos limites estabelecidos na legislação. A condutividade apresentou valores superiores ao indicado pela CETESB, caracterizando uma medida indireta da concentração de poluentes. Com os resultados obtidos no teste de micronúcleos pode-se observar uma maior frequência de micronúcleos nas células dos peixes capturados na represa, sugerindo que a água está contaminada por genotóxicos, que alteraram o material genético desses bioindicadores.
\end{abstract}

Palavras-chave: Eritrócitos de peixes, parâmetros de qualidade, ecossistema lentico.

\section{Micronucleus test in fish and physicochemical parameters in water at Cocais dam, Minas Gerais}

\begin{abstract}
The organisms known as bioindicators are used to assess changes in the aquatic environment. Incorporated chemical substances in natural environment interfere in the development of these organisms. The research had as objective to avaluate the water quality of the Cocais dam, in Patrocínio, Minas Gerais, using physical-chemical parameters of water and micronucleus test in fish. In this study were used fish of the species Oreochromis niloticus L. (Tilápia-do-nilo) introduced in the dam after its construction. Genetic material from twenty-eight individuals was collected at two points, P1 at the dam and P2 at the source. The cytological analysis was performed using an optical microscope and 4000 erythrocytes were examined per fish. For the physico-chemical characterization of the water samples were performed two collections during the rainy and dry periods, both in the dam and in the source. The parameters analyzed (turbidity, $\mathrm{pH}$, Dissolved oxygen - OD, total dissolved solids - SDT), nitrate ammoniacal Nitrogen values were lower than those established in the legislation. The conductivity was higher than value indicated by CETESB, characterizing an indirect measure of the concentration of pollutants. Whit the results obtained in the micronucleus test a higher frequency of micronucleus can be observed in the cells of the fish captured in the dam, suggesting that the water is contaminated by genotoxics, that altered the genetic material of these bioindicators.
\end{abstract}

Keywords: Erythrocytes of fish, quality parameter, lentic ecosystem.

\section{Introdução}

As ações antrópicas vêm causando grandes prejuízos ambientais nas últimas décadas, influenciando diretamente a qualidade da água, solo e ar. nesse sentido, o setor agrícola se destaca, uma vez que as monoculturas utilizam excessivamente de agroquímicos produzindo resíduos, os quais podem conter substâncias muitos poluentes (Correia et 
al., 2017). Os corpos d'água são expostos à pressão contínua das atividades humanas, assim realizar o monitoramento ambiental destes locais é essencial para manter o seu estado natural (Zalewska e Danowska, 2017).

No biomonitoramento, os bioindicadores são organismos como plantas, animais, fungos, bactérias, entre outros, que mostram respostas biológicas em longo prazo das condições ambientais e também de mudanças súbitas dos fatores intrínsecos ao ambiente. Os bioindicadores não apresentam informações sobre o grau de efeito adverso causado por estas alterações. Desses organismos, os peixes são frequentemente os mais convenientes para o monitoramento da poluição em ecossistemas aquáticos (Ramsdorf et al., 2012).

Os peixes são comumente utilizados como sentinelas devido ao seu papel na nutrição humana, e seu potencial de bioacumulação de substâncias genotóxicas, bem como a sua sensibilidade a baixas concentrações de mutagênicos (Deutschmann et al., 2016). Os peixes podem acumular poluentes diretamente da água contamina ou indiretamente pela ingestão de organismos aquáticos contaminados. Assim o poluente genotóxico pode afetar toda a cadeia alimentar aquática e por consequência o homem (Vasconcelos, 2012).

Uma forma de detectar a presença dos agentes genotóxicos é o teste de micronúcleos (MN), que vem sendo utilizado por ser uma técnica confiável, rápida e menos exigente tecnicamente do que a pontuação de aberrações cromossômicas. Assim, a utilização desse teste tem se tornado recorrente em programas de pesquisas ambientais para determinar alterações genéticas nos organismos em águas contaminadas e misturas complexas (Arslan et al., 2015).

De acordo com (Obiakor et al., 2012) os micronúcleos são corpos citoplasmáticos contendo cromatina, formados quando os fragmentos cromossômicos acêntricos se atrasam durante a anáfase e não se tornam incorporados nos núcleos das células filhas no processo de divisão celular. As alterações genéticas surgem como resultado de anormalidades cromossômicas ou do fuso, levando à formação de micronúcleos, que tendem a ser irreversíveis e continuam a se manifestar nas futuras gerações por meio da hereditariedade, podendo levar a redução na diversidade de espécies do ecossistema impactado.

Estudos nessa área são importantes, pois os peixes servem de alimento e alternativa de renda para a população em muitas regiões do país, sendo parte das tradições culturais de muitas comunidades, por serem fonte de proteína, minerais, oligoelementos, elementos essenciais, ácidos graxos, e ômega-3. No entanto, o consumo de peixe contaminado pode causar riscos à saúde humana devido às substâncias tóxicas presente em sua composição, como poluentes orgânicos persistentes (Silva, et al., 2016).

Nesse sentido, a pesquisa foi conduzida para avaliar a qualidade da água na represa Cocais, usando parâmetros físico-químicos de amostras de água e teste de micronucleos em peixes, dentro de uma escala espacial e temporal.

\section{Material e Métodos}

\section{Área de estudo}

A represa Cocais (Figura 1) está localizada na Fazenda Cocais no município de Patrocínio, Minas Gerais, situada a $19 \mathrm{Km}$ da BR 365. A área total da fazenda (coordenada geográficas $19^{\circ} 2^{\prime} 2^{\prime}$ 'S e $47^{\circ} 18^{\prime} 1^{\prime \prime} \mathrm{W}$ ) é de aproximadamente 20 ha sendo utilizada para a plantação e pastagem. Nos limites da fazenda foi construída a represa Cocais com objetivo de abastecer o pivot central, que irriga 29 ha da fazenda vizinha, onde são cultivados milho, feijão e soja ao longo do ano. Além da irrigação, as águas da represa estão sendo utilizadas para a criação de peixes que são comercializados na região.

Figura 1. Localização da área de estudo na represa Cocais, Patrocínio, Minas Gerias.

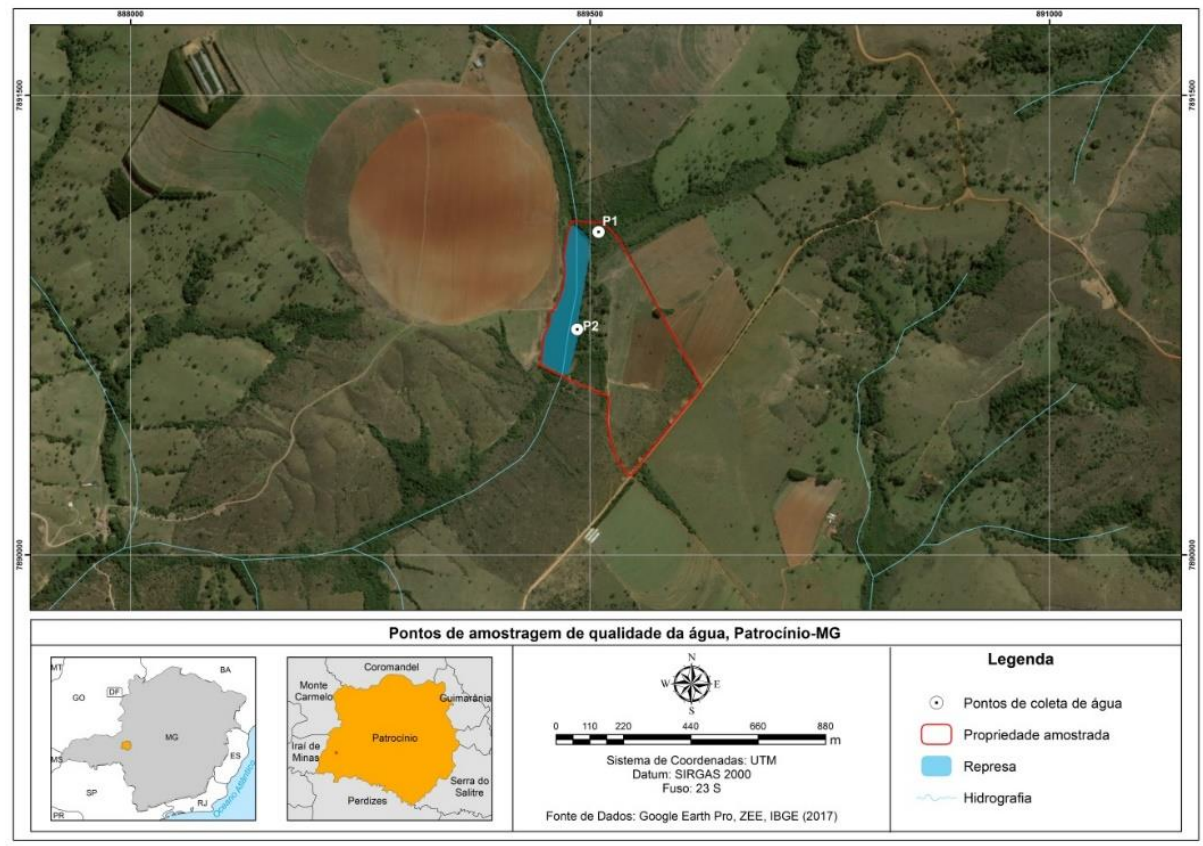

P1: ponto de coleta na nascente e P2: ponto de coleta na represa (mancha azul). 
A represa tem aproximadamente uma área de $38 \mathrm{~m}^{2}$ e $8 \mathrm{~m}$ de profundidade, com suas águas desaguando no reservatório da Usina Hidrelétrica de Nova Ponte. A Figura 1 apresenta a localização dos pontos de coleta de amostras de água e eritrócitos de peixe.

\section{Parâmetros físico-químicos das amostras de água}

Para caracterização físico-química da água, duas coletas foram realizadas, em cada ponto de coleta (P1: nascente e P2: represa). As coletas das amostras de água ocorreram no período de seca (outubro de 2016) e no período chuvoso (março de 2017). Foram avaliados, em triplicata, os seguintes parâmetros: condutividade, temperatura, potencial Hidrogeniônico $(\mathrm{pH})$, turbidez, Oxigênio Dissolvido (OD) e Sólidos Dissolvidos Totais (SDT), sendo utilizado um Multiparâmetros ( U-50, HORIBA). Essas análises visaram identificar espécies iônicas e elementos presentes no composto de análise, quantificando-os a fim de verificar os efeitos causados nos processos naturais e no meio ambiente (Parron et al., 2011).

Amostras de água coletadas na represa foram acondicionas em caixa térmica refrigerada para transporte e até serem armazenadas no laboratório. As análises de nitrato, nitrogênio amoniacal e nitrito foram realizadas de acordo com APHA (2012). Essas análises foram realizadas apenas no período de seca, por ser a época do ano em que as concentrações dos parâmetros alcançam os valores mais elevados.

\section{Teste de micronúcleos em peixes}

Para as análises biológicas de MN, o protocolo de pesquisa foi submetido ao Comitê de Ética para o Uso de Animais (CEUA) da Universidade Federal de Uberlândia, aprovado e registrado sob análise final $\mathrm{n}^{\circ} 100 / 15$ e 210/16. As coletas foram realizadas com o auxílio de varas de bambu, sob Licença de Pesca Científica, categoria "D" autorizada pelo Instituto Estadual de Florestas.

Os testes de micronúcleos foram realizados em peixes da espécie $O$. niloticus, conhecido como Tilápia do Nilo identificada pelo zoólogo taxonomista Francisco Langeani. Os peixes foram introduzidos no local, após a construção da represa, no ano de 2000. O material genético foi extraído de vinte e oito indivíduos em duas coletas. Na represa foram coletadas amostras de oito peixes no período de seca e oito peixes no período de chuva. Na nascente foram avaliados seis indivíduos em cada período.

O teste de micronúcleo foi realizado de acordo com os critérios descritos por Countryman e Heddle (1976) e Fenech (1993). Os peixes foram submetidos à extração de uma amostra de sangue, por meio de punção da veia caudal com auxílio de seringa heparinizada, para realização de esfregaço em lâminas, cinco lâminas por peixe. Em cada lâmina foi pingado cerca de $40 \mu \mathrm{L}$ de sangue, as mesmas foram secas à temperatura ambiente e após 24 horas fixadas em metanol $100 \%$ por 20 minutos. Em seguida, as lâminas foram coradas com solução Giemsa $4 \%$ diluída em tampão fosfato, $60 \mathrm{mM}$ $\mathrm{KH}_{2} \mathrm{PO}_{4}$ e $60 \mathrm{mM} \mathrm{Na}_{2} \mathrm{HPO}$, com pH 6.8, por 15 minutos. As lâminas foram lavadas com água destilada e secas em temperatura ambiente, e posteriormente preparadas para uso. A análise citológica foi realizada em microscópio óptico, magnificação de 1000x. Cerca de 4000 células de eritrócitos mononucleadas foram examinadas por peixe em cada lâmina (Vasconcelos, 2012). A Figura 2 apresenta MN de eritrócito de peixe, que sem alteração genética seria mononucleado.

Figura 2. Exemplo de Micronúcleo de O. niloticus sem alteração genética.

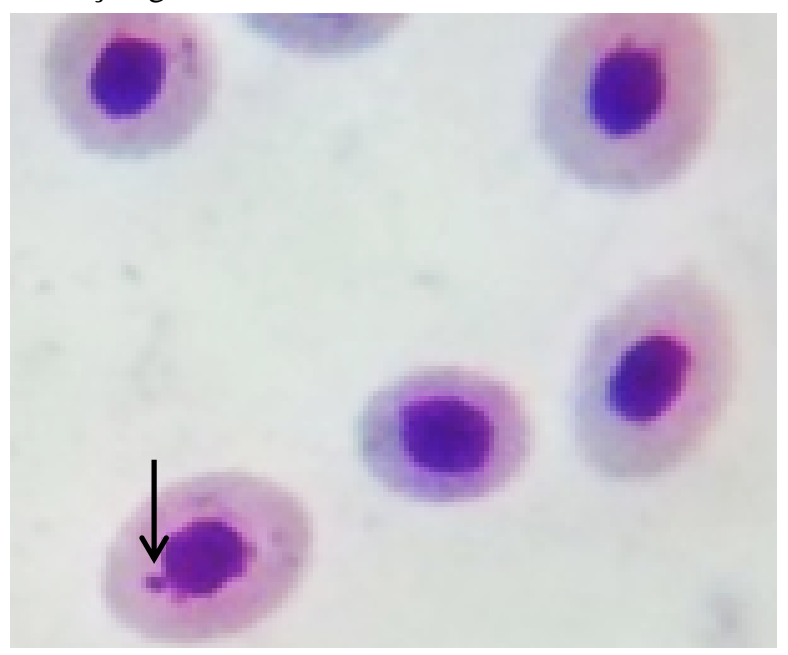

Fonte: Bueno, A. P. M.

\section{Análise estatística}

A Análise de Variância (ANOVA two way) foi utilizada para avaliar possíveis diferenças entre os locais de amostragem e variação de período, associada ao teste de Tukey e considerando o nível de significância de $p<0,05$. Os dados foram obtidos utilizando-se software Microsoft Excel 2007.

\section{Resultados e Discussão}

Os resultados das análises obtidas com o uso de Multiparâmetros estão apresentados na Tabela 1. Os parâmetros analisados, foram comparados com os valores estabelecidos na Resolução CONAMA 357/2005, para águas doces de Classe 2. Resultados semelhantes foram observados por Júnior (2014), em alguns pontos no rio Uberabinha, para pH e SDT, classificando esses valores como sendo de boa qualidade. Comportamento análogo se verificou, também, para a temperatura.

O OD variou de 8,39 à $9,80 \mathrm{mg} \mathrm{L}^{-1}$, não havendo tendência de variação espacial (represa e nascente) significativa entre as amostras. Segundo Azevedo (2014), em seu estudo usando Multiparâmetros, em corpo hídrico na fazenda São Gonçalo (Paraty, Rio de Janeiro), essa variação pode ocorrer por terem sidos aferidos em nível mais superficial da coluna d'água, onde os níveis de concentração são maiores, sendo que este elemento químico pode apresentar grandes variações em relação a profundidade e às estações anuais.

As concentrações de OD foram superiores aos limites estabelecidos pelo CONAMA, caracterizando um ambiente bem oxigenado e favorável à manutenção da vida aquática. 
Tabela 1. Valores (média \pm Desvio Padrão) de parâmetros físico-químicos de amostras de água coletadas na represa Cocais, Minas Gerais (2016).

\begin{tabular}{lccrrrr}
\hline \multirow{2}{*}{ Parâmetro } & \multirow{2}{*}{ Unidade } & $\begin{array}{c}\text { Resolução } \\
\text { CONAMA }\end{array}$ & \multicolumn{2}{c}{ Período Seco } & \multicolumn{2}{c}{ Período Chuvoso } \\
\cline { 4 - 7 } & & $357 / 2005$ & Represa $^{*}$ & Nascente* $^{*}$ & Represa * $^{*}$ & Nascente * \\
\hline Condutividade & $\mu \mathrm{S} \mathrm{cm}^{-1}$ & - & $163,67 \pm 18,99^{\mathrm{d}}$ & $348,67 \pm 7,57^{\mathrm{a}}$ & $220,00 \pm 2,83^{\mathrm{c}}$ & $241,33 \pm 4,93^{\mathrm{b}}$ \\
Temperatura & ${ }^{\circ} \mathrm{C}$ & - & $21,21 \pm 0,01^{\mathrm{b}}$ & $17,73 \pm 0,01^{\mathrm{d}}$ & $22,43 \pm 0,00^{\mathrm{a}}$ & $19,25 \pm 0,03^{\mathrm{c}}$ \\
Turbidez & $\mathrm{NTU}$ & 100 & $19,57 \pm 0,46^{\mathrm{b}}$ & $13,20 \pm 0,30^{\mathrm{d}}$ & $30,95 \pm 0,07^{\mathrm{a}}$ & $17,50 \pm 0,44^{\mathrm{c}}$ \\
pH & - & $6 \mathrm{a} 9$ & $7,84 \pm 0,17^{\mathrm{a}}$ & $6,33 \pm 0,14^{\mathrm{bc}}$ & $6,41 \pm 0,01^{\mathrm{b}}$ & $6,17 \pm 0,10^{\mathrm{bc}}$ \\
OD & $\mathrm{mg} \mathrm{L}^{-1}$ & $\geq 5$ & $9,80 \pm 0,47^{\mathrm{a}}$ & $9,43 \pm 0,09^{\mathrm{ab}}$ & $8,39 \pm 0,21$ & $9,52 \pm 0,02^{\mathrm{ab}}$ \\
SDT & $\mathrm{mg} \mathrm{L}^{-1}$ & 500 & $10,00 \pm 0,00^{\mathrm{d}}$ & $15,33 \pm 0,58^{\mathrm{b}}$ & $11,00 \pm 0,00^{\mathrm{c}}$ & $21,00 \pm 3,36^{\mathrm{a}}$ \\
\hline
\end{tabular}

Letras diferentes, na mesma linha, indicam médias significativamente diferentes pelo teste ANOVA, seguido pelo teste de Tukey $(\mathrm{p}<0,05)$.

A turbidez apresentou valores significativamente maiores na represa. No período chuvoso, meses de novembro a abril, é esperado turbidez mais altas devido aos processos naturais como as características geológicas, onde as chuvas podem carrear partículas de areia, silte e argila. Deve-se também, levar em consideração a possível ausência do manejo adequado do solo na agricultura, que acentua os processos naturais.

A condutividade variou na represa de $157 \mu \mathrm{S} \mathrm{cm}^{-1}$ a 218 $\mu \mathrm{S} \mathrm{cm}{ }^{-1}$, sendo maior no período chuvoso. A condutividade indica a quantidade de sais existentes na coluna d'água, representa uma medida indireta da concentração de poluentes. Valores superiores a $100 \mu \mathrm{S} / \mathrm{cm}$ indicam ambientes impactados (CETESB, 2009).

O nitrato variou de $1,4 \mathrm{mg} \mathrm{L}^{-1}$, na represa, e $6,6 \mathrm{mg} \mathrm{L}^{-1}$ (Tabela 2), na nascente. Enquanto que, o nitrogênio variou de $0,46 \mathrm{mg} \mathrm{L}^{-1}$ na nascente a $0,65 \mathrm{mg} \mathrm{L}^{-1}$ na represa, mas sem superarem o valor estabelecido pelo CONAMA.

Tabela 2. Concentrações, em $\mathrm{mg} \mathrm{L}^{-1}$, de no nitrato, nitrogênio (N) amoniacal, nitrito e DGO de amostras de água coletadas na represa Cocais, Minas Gerais (2016) e os limites máximos (LM) estabelecidos pela Resolução CONAMA (357/2005).

\begin{tabular}{lccc}
\hline \multirow{2}{*}{ Parâmetros } & LM & \multicolumn{2}{c}{ Período Seco } \\
\cline { 3 - 4 } & & Represa & Nascente \\
\hline Nitrato & 10,0 & 1,4 & 6,6 \\
N Amoniacal & 3,7 & 0,7 & 0,5 \\
Nitrito & 1,0 & 4,0 & 3,0 \\
\hline
\end{tabular}

Para o nitrito observou-se valores bem elevados em relação aos limites estabelecidos pela Resolução CONAMA 357/2005. Segundo Costa (2016), o nitrogênio sofre processos oxidativos tendo como subproduto os nitritos e nitratos. O nitrito é um elemento instável que se transforma em nitrato com rapidez e seu aumento se da devido ao uso excessivo de fertilizantes à base de nitrogênio provocando a lixiviação deste elemento ameaçando a qualidade da água, especialmente em áreas agrícolas, onde as elevadas concentrações são comuns.

Os resultados obtidos para os testes de $\mathrm{MN}$ nos dois pontos analisados, P1 na nascente e P2 na represa, nas estações seca e chuvosa, estão descritos na Tabela 3. No total, 112.000 eritrócitos de sangue de 28 peixes foram analisados. O ponto de coleta P2, localizado na represa, apresentou número superior de micronúcleos nas células analisadas em comparação ao ponto P1, na nascente, para ambas as estações. A Figura 1 ilustra que a nascente está localizada acima da represa, em uma área relativamente mais preservada, com mata ciliar no entorno.

Silva et al. (2015) em seu trabalho sobre o impacto da poluição na água em espécies de peixes no sudeste do Estado do Goiás, para pontos em condições similares, obteve resultados semelhantes aos dos pontos P1 e P2 do presente estudo.

A análise de variância revelou que as frequências de MN não houve diferenças temporal significantes, estações seca e chuvosas do mesmo ponto de coleta. No entanto, houve diferenças nas frequências em relação à escala espacial, entre os pontos de coleta $\left(\mathrm{P}_{1}, \mathrm{P}_{2}\right)$.

Pimenta (2012) encontrou resultados estatísticos semelhantes para dois pontos amostrados em seus estudos no rio Paraguai, demostrando assim que a escala espacial foi mais significativa que a temporal.

Tabela 3. Total de micronúcleo (MN) em eritrócitos de peixes coletados (n), no período seco e chuvoso, na represa Cocais, Minas Gerais (2016).

\begin{tabular}{lcccc}
\hline $\begin{array}{c}\text { Ponto de } \\
\text { coleta }\end{array}$ & $\mathrm{n}$ & $\begin{array}{c}\text { Total de } \\
\text { células }\end{array}$ & $\begin{array}{c}\text { Total de } \\
\text { MN }\end{array}$ & $\begin{array}{c}\text { Média } \pm \text { Desvio } \\
\text { Padrão }\end{array}$ \\
\hline P1Seca & 8 & 32000 & 2 & $4,12 \pm 1,46^{\mathrm{a}}$ \\
P1Chuva & 8 & 32000 & 1 & $3,25 \pm 1,49^{\mathrm{a}}$ \\
P2 Seca & 6 & 24000 & 33 & $0,33 \pm 0,52^{\mathrm{b}}$ \\
P2Chuvas & 6 & 24000 & 26 & $0,17 \pm 0,41^{\mathrm{b}}$ \\
\hline
\end{tabular}

Letras diferentes, na coluna, indicam médias significativamente diferentes pelo teste ANOVA, seguido pelo teste de Tukey $(\mathrm{p}<0,05)$.

A elevada frequência de micronúcleos encontrados em células dos peixes sugere que a exposição a estes agentes genotóxicos está causando alterações genéticas nos peixes. O ponto de coleta P1, utilizado como controle negativo, consiste em uma região de natureza preservada, apresentando quantidades de $\mathrm{MN}$ significativamente reduzidas ao comparar com o ponto $\mathrm{P} 2$, o que indica que as águas, neste ponto, estão sem grande influência da ação de poluentes e são de melhor qualidade. Ainda segundo Silva et al. (2015), a alimentação dos indivíduos considerados onívoros pode interferir nos resultados. 


\section{Conclusões}

Não foram encontrados valores significativos para os parâmetros físico-químicos se mantiveram a maioria dentro da Resolução CONAMA 357/2007. No entanto, um número significativo de MN foi encontrado nos eritrócitos de peixes. $\mathrm{O}$ teste de micronúcleos mostrou-se adequado para a avaliação da qualidade da água. Estudos complementares, como inclusão da análise de sedimentos e metais são recomendados, para caracterizar a contaminação difusa e a extensão do problema na represa.

\section{Agradecimentos}

Ao Instituto de Ciências Agrárias, ao Instituto de Química, ao Instituto de Genética e Bioquímica da Universidade Federal de Uberlândia, pelo incentivo a pesquisa.

\section{Referências}

APHA, 2012. Standard Methods for The Examination of Water and Wastewater, 22nd Ed.: American Public Health Association, American Water Works Association, Water Environment Federation. Washington, DC.

Arslan, O. C.; Boyacioglu, M.; Parlak, H.; Katalay, S.; Karaaslan, M. A. 2015. Assessment of micronuclei induction in peripheral blood and gill cells of some fish species from Aliağa Bay Turkey. Marine Pollution Bulletin,94: 48-54.

Azevedo, S. M. C.; Vasconcelos, D. V.; Avelar, J. C. L. 2014. Análises físicoquímicas do corpo hídrico na fazenda São Gonçalo em Paraty (RJ). IberoAmericana de Ciências Ambientais, 5(1).

BRASIL. Ministério do Meio Ambiente. Resolução CONAMA n 357 de 17/03/2005. Alterada pela Resolução 410/2009 e pela 430/2011. Acessado em 19 de setembro de 2016.

CETESB. Companhia de Tecnologia de Saneamento Ambiental. Relatório de Qualidade das Águas Interiores do Estado de São Paulo. Série Relatórios. Apêndice A: Significado Ambiental e Sanitário das Variáveis de Qualidade das Águas e dos Sedimentos e Metodologias Analíticas e de Amostragem. 2009.

Contryman, P. I., Heddle, J. A. The production of micronuclei from chrosome aberrations in arradiated cultures of human lymphocytes. Mutation Research, v. 41, p. 321-332. 1976.

Correia, J. E.; Chistofoletti, C. A.; rodriguez, Y. A.; guedes, T.A.; fontanetti, C. S. 2017.Comet assay and micronucleus tests on Oreochromis niloticus (Perciforme: Cichlidae) exposed to raw sugarcane vinasse and to phisicochemical treated vinasse by $\mathrm{pH}$ adjustment with lime $(\mathrm{CaO})$. Chemosphere, 173: 494-501.

Costa, D. D.; Kempka, A. P.; Skoronski, E. 2016. A contaminação de mananciais de abastecimento pelo nitrato: O panorama do problema no Brasil, suas consequências e as soluções potenciais. Revista Eletrônica do PRODEMA Fortaleza, Brasil, 10(2): 49-61.

Deutschmann, B,; Kolarevic, S.; Brack, W.; Kaisarevic, S.; Kostic, j. 2016. Longitudinal profile of the genotoxic potential of the River Danube on erythrocytes of wild common bleak (Alburnus alburnus) assessed using the comet and micronucleus assay B. Science of the Total Environment,.573: 1441-1449.

Fenech, M. 1993. The cytokinesis-blockmicronucleus technique: a detailed description of the method and its application to genotoxicity studies in human populations. Mutat. Res. v. 285, p. 35-44.

Júnior, E. O. C.; Pereir, B. B.; Morelli, S.; Pavanin, E. V.; Pavanin, L. A. 2016 Biological monitoring and $\mathrm{B}$ chromosomefrequency in Bagre (Rhamdia quelen) in southeast Brazil. Environmental Toxicology end Fharmacology, 38: 510-517.

Obiakor,, M. O.;Okonkwo, J. C.; Nnabude, P. C. Ezeonyejiaku, C. D. 2012. Eco-genotoxicology: Micronucleus Assay in Fish Erythrocytes as In situ Aquatic Pollution Biomarker: a Review. Journal of Animal Science Advances, 2(1): 123-133.

Parron, L. M.; Muniz, D. H. F.; Pereiea, C. M. 2011. Manual de procedimentos de amostragem e análise físico-química de água.

Pimenta, V. M. S. D.; Silva, J. M.; Nepomuceno, J. C.; Pavanin, L. P. 2013. In Situ Assessment of the Paraguay River Water, in Brazilian Pantanal, by Means of Micronucleus Assay with Fish and Chemical Analysis. Bull Environ Contam Toxicol, 90:427-433.
Ramsdorf, W. A.; Vicari, T.; Almeida, M. I. M.; Artoni, R. F.; Cestari, M. M. 2012. Handlingof Astyanax sp. for biomonitoring in Cangüiri Farm within a fountainhead (Iraí River Environment Preservation Area) through the use of genetic biomarkers. Environ Monit Assess, 184: 58415849 .

Silva, E.; Fernanda. N. Costa, F. N.; Souza, T. L.; Viana, Z. C. V.; Souza, A. S.; Korn, M. G. A.; Ferreira, S.L.C. 2016. Assessment of Trace Elements in Tissues of Fish Species: Multivariate Study and Safety Evaluation, 27(12): 2234-2245.

Silva, S. V. S.; Dias, A. H. C.; Dutra, E. S.; Pavanin, A. L.; Morelli, S.; Pereira, B. B. 2015.The impact of water pollution on fish species in southeast region of Goiás, Brazil. Journal of Toxicology and Environmental Health, 79: 8-16.

Vasconcelos, M.G. Avaliação integrada da qualidade da água do Rio Uberabinha - MG com base na caracterização química dos sedimentos e de espécimes da ictiofauna. 2012. 188 f. Tese (Doutorado em Ciências Exatas e da Terra) - Universidade Federal de Uberlândia, Uberlândia, 2012. Acesso em: 15 de setembro de 2016.

Zalewska, T.; Danowska, B. 2017. Marine environment status assessment based on macrophytobenthic plants as bioindicators of heavy metals pollution. Marine Pollution Bulletin, 118: 281-288. 